\title{
FUENTES CHINAS DEL MARFIL HISPANO-FILIPINO: COMERCIO, MIGRACIÓN E INTERCAMBIOS CULTURALES ${ }^{1}$
}

Zhou Meng

Universidad de Granada

Data recepción: 2019-10-05

Data aceptación: 2020-03-05

Contacto autora: esperanza0929@outlook.com

ORCID: https://orcid.org/0000-0001-6416-1004

\section{RESUMEN}

Este artículo tiene como objetivo buscar las fuentes chinas del marfil hispano-filipino, piezas hechas por los artesanos chinos en Manila por encargo de los españoles durante el dominio hispánico en Filipinas. La mayoría de estos artistas procedían de Zhangzhou, ciudad que tuvo una emergente industria de marfil y abundantes relaciones comerciales con Manila en aquella época. En este texto abordaremos las actividades comerciales y la emigración de Zhangzhou a Manila, las relaciones entre la eboraria hispano-filipina y el marfil de Zhangzhou, y, sobre todo, las relaciones formales entre la figura la Virgen María y la de Guanyin, cuyas interacciones iconográficas nos ayudan a comprender mejor estos intercambios culturales.

Palabras clave: marfil hispano-filipino, escultura marfileña de Zhangzhou, sangley, comercio, intercambio cultural

\section{ABSTRACT}

This article aims to identify the Chinese sources of Hispano-Philippine ivory, pieces fashioned by Chinese artisans in Manila for the Spanish during their rule in the Philippines. Most of these artists came from Zhangzhou, a city with an emerging ivory industry and extensive commercial ties with Manila at that time. We will address commercial activities and emigration from Zhangzhou to Manila, the links between Hispano-Philippine ivory and Zhangzhou ivory, and, above all, the formal relationships between the figures of the Madonna and Guanyin, whose iconographic interactions help provide a better understanding of these cultural exchanges.

Keywords: Hispano-Philippine ivory, Zhangzhou ivory carving, sangley, trade, cultural exchange

\section{Introducción y metodología}

Dentro de los objetos llegados en el Galeón de Manila, los marfiles hispano-filipinos son los que mejor manifiestan los intercambios culturales surgidos entre Occidente y Oriente. Estas figuras, hechas según los modelos traídos por los españoles desde Europa, han demostrado bastantes características del arte asiático ya que es habitual que presenten rasgos anatómicos chinos: ojos abultados y oblicuos, párpados superiores grue- sos, lóbulos de orejas demasiado alargados y nariz de aletas carnosas (fig. 1) (Ruiz Gutiérrez 2013, 195). Suelen presentar, además, el cuello cilíndrico con tres arrugas como en las representaciones budistas y motivos decorativos orientales como nubes escamosas o vegetación con técnicas similares a las formas de presentación en la pintura china (Estella Marcos 1970, 161).

Los autores de estas obras, llamados "sangleyes" por los españoles, son los artesanos chinos 


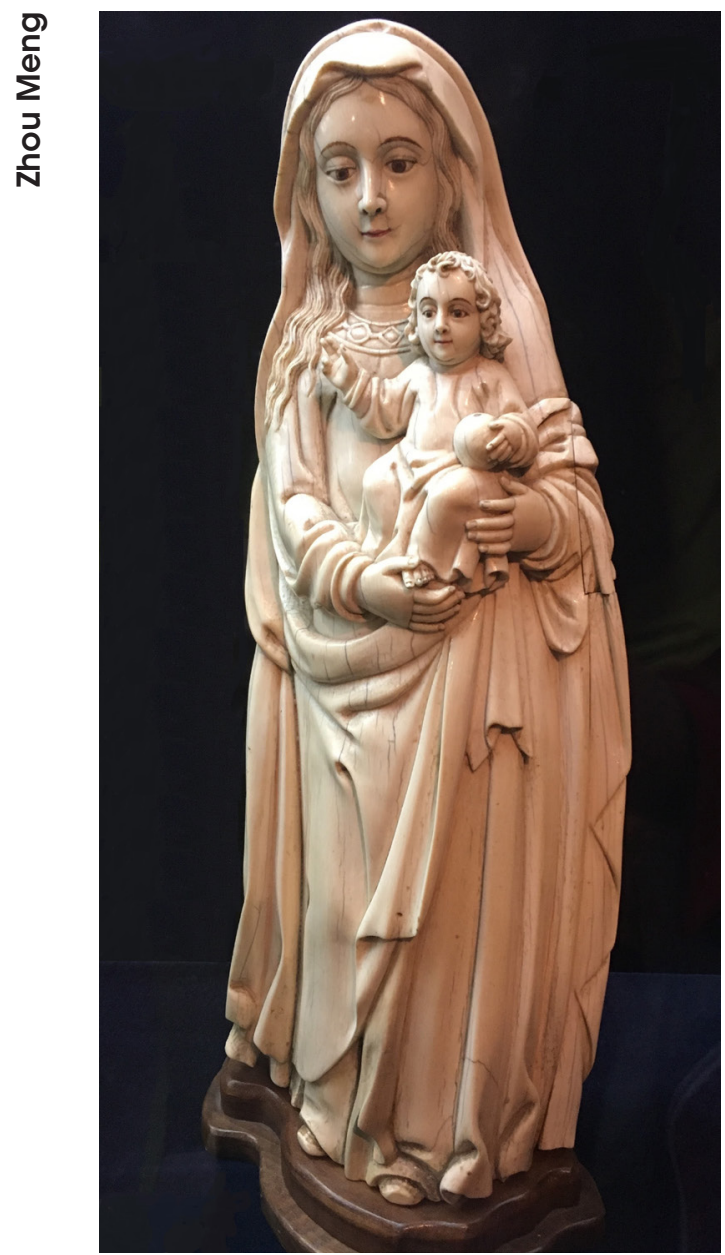

Fig. 1. Virgen con el Niño, siglo XVII, marfil, Museo Oriental, Valladolid (fotografía de la autora)

establecidos en Filipinas. En 1571, Legazpi estableció la capital de las Islas Filipinas en la recién conquistada ciudad de Manila convirtiéndola desde ese momento en el puerto de partida de la ruta transpacífica que enlazaba Filipinas con México. La gran demanda del mercado hispánico pronto atrajo a los comerciantes chinos, quienes transportaron todo tipo de mercancías chinas a Manila para hacer negocios con los españoles (Fang 2012, 176-81). Con el tiempo los chinos que iban estableciéndose en Manila aumentaron en gran número y se encargaron de "todos los oficios y artes mecánicas" (Salazar 1897, 64). Las imágenes religiosas que hicieron estos sangleyes mostraban una gran habilidad artesanal, razón por la que los españoles nunca dejaron de encargarles nuevas obras. En una carta dirigida al rey en 1590, Domingo de Salazar, primer obispo de Manila, manifiesta que era tal "la abilidad que muestran al retratar las ymágines que bienen de España" que pronto no serían necesarias "las que se haçen en Flandes" (Salazar 1897, 66).

La mayoría de los chinos establecidos en Manila provenían de Zhangzhou y Quanzhou, en la provincia de Fujian, una región al sureste de China que tuvo una gran tradición en el campo de las artes escultóricas. En 1567, dos años después de que los españoles conquistaran Cebú, el gobierno de la entonces dinastía Ming (1368-1644) levantó la prohibición que pesaba sobre el libre comercio marítimo y definió el puerto de Zhangzhou como el único autorizado para el comercio exterior. Con la posibilidad de introducir colmillos desde ultramar, en Zhangzhou surgió una interesante industria de marfil. Los artesanos de Zhangzhou empezaron a tallar figuras religiosas chinas en marfil, algo insólito hasta ese momento.

El hecho de que estas piezas fueran creadas coincidiendo con el surgimiento de la eboraria hispano-filipina ha inspirado la sospecha de una posible interrelación entre ambas. Aunque es bien conocido que los marfiles hispano-filipinos fueron manufacturados por artesanos chinos, tema estudiado por Margarita Estella (Estella Marcos 1967; Estella Marcos 1970; Estella Marcos 1984 a; Estella Marcos 1984 b; Estella Marcos 1989), pocos estudiosos han analizado sus fuentes en China. ${ }^{2}$ Además, se ha minusvalorado el impacto del arte de Fujian en ellos, especialmente en lo que respecta a su relación con el marfil doméstico de Zhangzhou. ${ }^{3}$ Las piezas de eboraria, hechas por los artesanos de Fujian, tanto de iconografía cristiana como de figuras religiosas chinas, están estrechamente vinculadas entre sí. El ejemplo más claro lo encontramos al comparar las imágenes de la Virgen y de Guanyin, figura del budismo chino, pues ambas presentan una serie de coincidencias iconográficas que nos hablan de estos transvases culturales. ${ }^{4}$ Además, esto ocurrió en un momento histórico en el que los europeos intentaban llamar a la puerta de Asia Oriental mientras que China empezó a abrirse al mundo, a 
través del comercio y las migraciones entre Fujian y Filipinas.

Con el objetivo de buscar las fuentes chinas del marfil hispano-filipino, en este artículo vamos a centrarnos en analizar las relaciones establecidas entre Zhangzhou y Manila explorando los intercambios culturales que se produjeron, y, sobre todo, las relaciones existentes entre la eboraria hispano-filipina y el marfil de Zhangzhou. Para ello prestaremos una especial atención a las interacciones iconográficas existentes entre las figuras de la Virgen y Guanyin, ya que nos revelan con claridad los intercambios artísticos que se produjeron. Utilizaremos para ello distintas fuentes, desde documentos españoles a corografías chinas pasando por los diarios de los miembros de Compañía Neerlandesa de las Indias Orientales, todo lo cual nos ayuda a comprender lo sucedido desde un punto de vista global.

\section{El puerto de la Luna de Zhangzhou: lugar de origen del comercio y de la migración}

Cuando los españoles se establecieron en las Islas Filipinas, enseguida trataron de obtener los codiciados productos de Asia Oriental. El apetito comercial de España debió de estimularse a la vista de las embarcaciones tradicionales malayas, los denominados "praos", que iban cargados de sedas y porcelana (Shurtz 1992, 62). Así, en una carta al rey Felipe II escrita en 1567, Legazpi propuso "correr la costa de la China y contratar con la Tierra Firme", lo que en su opinión sería muy provechoso "y de grande efeto". 5

El sueño de Legazpi se haría realidad muy pronto, aunque él no llegó a verlo debido a su repentina muerte, acaecida en 1572. En 1567, justamente el mismo año en que Legazpi expresó su deseo de comerciar con China, este país, muy visitado por la fantasía de los europeos desde las descripciones de Marco Polo, llevó a cabo una reforma que afectaría a la historia global. Como hemos avanzado, el gobierno Ming abolió la prohibición que pesaba sobre el libre comercio marítimo -vigente por casi dos siglos a partir de la fundación de la dinastía en 1368- y consagró el puerto de la Luna en la ciudad de Zhangzhou como el único lugar autorizado para estos intercambios. Esto supuso que los mercaderes priva- dos pudieran realizar negocios con otros territorios de ultramar.

Situado en la desembocadura del Río Jiulong, que cruzaba el sur de Fujian, el puerto de la Luna fue bautizado así por su forma geográfica, parecida a la de este cuerpo celeste (Li 2001, 5). En una provincia montañosa como Fujian donde faltan tierras cultivables, los habitantes tuvieron que vivir del mar, manteniendo una importante tradición de comercio marítimo a lo largo de su historia. Por eso, aún con la prohibición gubernamental la gente de Zhangzhou continuó con los negocios de forma ilegal. El lugar era ideal para ello ya que el puerto de la Luna poseía una costa sinuosa y una posición relativamente interior conveniente para esconder cualquier tipo de barco y escapar de la vigilancia oficial.

La legalización del comercio exterior en 1567 coincidió con la demanda de los españoles, satisfaciendo las exigencias del mercado americano a través de la ruta transpacífica. Al mismo tiempo se promovió el asentamiento español en Filipinas, cuya tierra estéril generaba muy poco beneficio por sí misma. Fue en este contexto histórico que los comerciantes de Zhangzhou y Quanzhou, ambos del sur de Fujian, empezaron a frecuentar la Isla de Luzón, donde arribaban en siete u ocho días (Fang 2007, 138). Las mercancías chinas fueron cargadas posteriormente en el famoso Galeón de Manila, también Ilamada Nao de China en Nueva España, lugar de destino del galeón (Shurtz 1992, 93).

Pese a la apertura del puerto de la Luna, los comercios con el ultramar no fueron totalmente libres en China, sino que, estuvieron bajo el control gubernamental. Cada año, el gobierno chino emitió un cierto número de permisos, llamado "shangyin", que fueron distribuidos entre los barcos según el destino al que se dirigían. La ley promulgada en 1589 permitía la actividad de 44 barcos en el Océano Este y otros 44 en el Océano Oeste, ${ }^{6}$ sumando un total de 88 (Gu 1962, 3939). La primera de estas partidas incluía a su vez 16 permisos para la isla de Luzón dada su cercanía (Gu 1962, 3939). Sin embargo, la documentación revela que no siempre se seguían estas directrices: "Apenas hay barcos que llegan allá [Océano Oeste], y los que obtienen el permiso para ese lugar, secretamente negocian en Luzón, a lo mejor 
por la cercanía de la isla y las buenas ganancias que obtienen en ese lugar." (Institute of History and Philology 1987, 67). Es decir, la mayoría de los barcos que obtuvieron el permiso prefirieron dirigirse a negociar a Luzón, eso sin hablar del tráfico ilegal que aún continuaba desarrollándose debido a que el corto número de licencias concedidas nunca cubrió la demanda real.

Por razones comerciales, una parte de los comerciantes chinos se establecieron en Manila. Según Dongxiyangkao, "Los chinos [que] acuden a negociar frecuentemente a Luzón, suelen permanecer allí por un largo tiempo, llamándolo yadong. ${ }^{7}$ Se reúnen gradualmente a vivir en el Parián, hasta llegar a unas diez mil de personas, de las cuales algunas tienen el pelo cortado [para convertirse al cristianismo] e incluso tienen hijos allí." (Zhang 1981, 89). En 1570, cuando el maese de campo Martín de Goiti llegó a Luzón, encontró que "vivían en el quarenta chinos casados" ${ }^{8}$ mientras que en 1572 el número de chinos llegó a ser de "ciento cinquenta ombres y mugeres".. Para completar estos datos, debemos tener en cuenta que en 1588 la población china de Manila se estimó en unas diez mil personas.10

\section{Suposición sobre el origen de los marfiles hispano-filipinos}

Los chinos, con su prevalencia en la cantidad y su capacidad de aprendizaje pronto se convirtieron en "oficiales de todos los oficios" (Salazar 1897, 64). Eran sastres, zapateros, plateros, escultores, pintores, bordadores, hilanderos, etc., y su aportación fue tal que se llegó a afirmar que sin ellos "la ciudad no podía mantenerse" (Shurtz 1992, 113). El proceso de evangelización de las Islas Filipinas, misión que acometieron las órdenes religiosas de forma simultánea a la conquista de las islas, requirió una gran cantidad de piezas religiosas, tarea que se encargaba, como siempre, a los artesanos chinos.

Un documento importante que registra la manufactura de figuras cristianas por los chinos es la relación de Hernando Riquel fechada en 1574, donde se relata que "vinieron 3 navíos de China que truxeron Mercadurias della", y, aparte de los consabidos envíos de seda y porcelana, "traxeron Imagenes de Crucifixos, Sillas muy curiosas á nuestro modo." "Es difícil saber qué modelos usaron los chinos para la realización de estos crucificados en una época tan temprana, máxime si tenemos en cuenta que la fe cristiana no comenzaría a difundirse por China hasta la llegada del fraile jesuita Matteo Ricci, quién estableció la primera misión en Zhaoqing en 1583. Sin embargo, un documento del siglo XVI nos puede dar una pista sobre el origen de esta industria.

En 1561, el misionero jesuita Luis Frois escribió una carta dirigida a Gonzalo Vaz donde relataba la historia de un hidalgo portugués que estuvo cautivo en China durante 1549-1553. En ella se afirmaba que los chinos, guiados por un fin comercial, habían realizado pinturas de temática cristiana que luego habían llegado a Goa para adornar las habitaciones de los hermanos (Medina 1995, 475-76). Este hidalgo fue Galeote Pereira, prisionero de la batalla de Zoumaxi (1549) que enfrentó a portugueses y chinos en Zhangzhou (Wicki 1958, 355). ${ }^{2}$ Después de ser capturado, Pereira fue recluido en la cárcel de Fuzhou, capital de la Provincia de Fujian que está al norte de Zhangzhou. Por eso, lo relatado en la carta pudo ocurrir al sur de Fujian, muy probablemente cerca de Zhangzhou.

El informe de Pereira demuestra que, a mediados del siglo XVI, ya existía una industria al sur de Fujian en la que se producían objetos de arte cristiano para ser suministrados al mundo católico. Esta circunstancia quizá se deba a la demanda de los portugueses ya que habían mantenido cierto comercio ilegal durante varias décadas en las costas de Zhejiang y Fujian tras fracasar sus intentos de establecer negocios con el gobierno Ming entre 1517-1522. Esta idea se refuerza si tenemos en cuenta que cuando finalmente lograron establecerse en Macao (1557), rápidamente se implementaron talleres en el sur de China, elaborándose figuras cristianas con colmillos transportados desde Goa. Estas piezas se correspondían con el llamado "marfil luso-oriental", o más concretamente, el "marfil sino-portugués" según la clasificación de Bernado Ferrão (Tavares e Távora 1983, XVIII). Por falta de datos documentales, no se sabe el lugar de producción de estas figuras, aunque también presentan obvios elementos chinos. Según Gillman, es posible que este enclave fuera Cantón, ciudad que en el siglo XVIII se convertiría en un centro productivo 
especialmente dedicado a la exportación (Gillman 1984, 36).

A través de estos contactos con los portugueses, los fujianeses pudieron ser los primeros chinos que conocieron las figuras cristianas ya que se trata de un periodo anterior a la evangelización de Filipinas por parte de los españoles. De igual modo, con las ventajas geográficas que les facilitaban el contacto con el extranjero, fueron los primeros fujianeses convertidos al cristianismo quienes introdujeron la nueva religión en su tierra natal. En el prólogo de la obra evangélica Qike redactada por el jesuita Diego de Pantoja, el funcionario Chen Liangcai, oriundo de Quanzhou (Fujian), uno de los lugares de procedencia de los sangleyes, relata lo siguiente: "Cuando yo era niño, oí algo sobre el cristianismo. Los paisanos de mi pueblo natal, que viajaban mucho por el mar, y que tenían contactos con los extranjeros, cuando volvieron, me contaron cosas de la religión de Jesucristo..." (Chen 2013, 303-4). Si tenemos en cuenta que Chen nació en 1569 (Museo de Tianyige 2006, 14), entonces su "infancia" debió transcurrir durante las décadas de 1570 y 1580, época inicial del establecimiento chino en Manila. Es posible que los "paisanos" de los que habla, convertidos al cristianismo en Luzón, también trajeran imágenes de Cristo Crucificado o de la Virgen proporcionadas por los españoles, las cuales pudieron servir como modelos para que los artistas locales las copiaran.

En cuanto al lugar de manufactura de los marfiles hispano-filipinos, además de los talleres en Manila, varios investigadores han propuesto que su procedencia puede ser Fujian. Fernando Zóbel propone que "algunas imágenes, sobre todo estatuas de marfil, fueron hechas en el sur de China para ser exportadas a Filipinas y Sudamérica." (Zóbel de Ayala 1963, 15). Gillman también supone que los marfiles encontrados en las iglesias coloniales de Filipinas, estaban hechos en realidad en los talleres de Fujian (Gillman 1984, 38). Aunque de momento es difícil encontrar testimonios más directos para comprobar esta suposición, la carta de Frois y el relato de Chen Liangcai nos proporcionan interesantes indicios en este sentido. Además, el hecho de que surgieran sendas industrias de marfil tanto en Manila como en Zhangzhou nos hace pensar en un lógi-

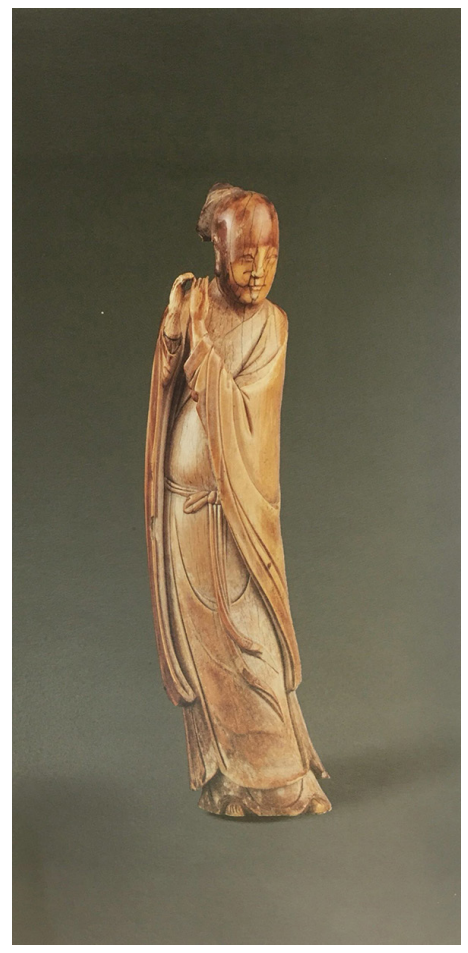

Fig. 2. Han Xiangzi (Personaje de los Ocho Inmortales), 15731644, marfil, Colección privada (Fuente: Gao, Meiqing, ed., Chinese Ivories from the Kwan Collection (關氏所藏中國牙雕) (Hong Kong: Art Gallery-the Chinese University of Hong Kong, 1990), 169)

co enlace entre ambas. Los grabadores de Fujian, que mantuvieron una complicada relación tanto con su tierra natal como con Filipinas, combinaron la tecnología escultórica de ambos entornos culturales creando obras que catalogamos como "arte hispano-filipino" a la vez que dejaron en sus propias resonancias en el arte chino.

\section{El marfil de Zhangzhou: artesanía surgida al calor de los negocios marítimos}

La mayoría de los artesanos chinos en Manila fueron llamados "sangleyes", término posiblemente procedente del dialecto minnanhua del sur de Fujian (Ollé 2002, 24). La provincia de Fujian era conocida como "pueblo de escultura" dada su larga tradición en esta disciplina artística, siendo buen ejemplo de ello la artesanía folklórica en piedra de Shoushan y la escultura de madera de Putian, manifestaciones que se influirían entre sí 
a partir de la dinastía Tang (618-907). ${ }^{13}$ En ese sentido, no sorprende que las figuras cristianas hechas por los sangleyes demuestren tanta influencia del arte chino. Además, a partir de la segunda mitad del siglo XVI, el florecimiento del comercio exterior de Zhangzhou ofreció un buen ambiente para el desarrollo de los distintos tipos de escultura, aprovechando las abundantes materias preciosas importadas para la creación de nuevas obras.

En las postrimerías de la dinastía Ming (15671644), el único puerto legítimo de comercio exterior fue Zhangzhou, lo que justifica la llegada a él de una gran cantidad de marfil importado. El literato fujianés Xu Bo (1563-1639) describió el puerto de la Luna aludiendo a su prosperidad: "[Las] mercancías transitan [con los] viajeros, [y los] comerciantes ricos reúnen [esas] riquezas. [Se] tallan los cuernos de rinoceronte hábilmente, [mientras el] marfil pulido resplandece" (Shen 2000, 984). ${ }^{14}$ Dicho poema confirma el impacto del comercio ultramarino en Zhangzhou y el surgimiento de una industria de escultura suntuaria labrada en materiales preciosos como cuerno de rinoceronte y marfil. Al respecto es digno de mención el registro de la cartografía de Zhangzhou publicado en 1628 :

El marfil no se encuentra en nuestra prefectura, siempre es comprado a los comerciantes que lo importan al puerto. La gente de Zhangzhou lo talla en figuras de inmortales y cosas de este tipo con el fin de darse un placer. Tienen las orejas, ojos y miembros muy vivos, y las manufacturadas en Haicheng son excepcionalmente ingeniosas (Min 2012, 1835). ${ }^{15}$

Este texto revela que las "figuras de inmortales" talladas en marfil por los escultores de Zhangzhou eran muy famosas, alusión que se refiere a las imágenes procedentes del budismo y del taoísmo como Guanyin y los Ocho Inmortales. Estas figuras suelen tener los cinco sentidos muy concentrados en una cara relativamente amplia y los bordes de las túnicas redondeadas, frecuentemente coloreados. El cuerpo se inclina según la forma natural del colmillo, mostrando una elegancia confortable (fig. 2). El hecho de que no existan registros sobre este tipo de figuras de marfil en las cartografías de otras regiones de la misma época y que presenten una gran semejanza con las esculturas de piedra o de porcelana de Fujian (fig. 4), ha llevado a que sean consideradas siempre como obras de Zhangzhou (Cai 2005, 39-87).

El literato Gao Lian, que vivía en Hangzhou durante el reinado de Wanli (1573-1620), hace notar en su obra Zunshengbajian que "La figura de marfil de Fujian posee una hechura ingeniosa, lamentablemente no hay lugar para que se coloque y ni siquiera se aprecia como de buen gusto" (Gao 1994, 552). Esta descripción indica que la figura de marfil de Fujian gozaba de buena fama fuera de la provincia, sobre todo por su ingeniosidad.

Según Gillman, en la corografía de Zhangzhou publicada en 1573 todavía no aparece ninguna alusión al marfil, sin embargo, la obra de Gao Lian publicada en 1591 ya sí habla de ello (Gillman 1984, 38). Esto nos lleva a pensar que la industria de marfil de Zhangzhou pudo surgir entre los años 70 y 90 del siglo XVI, momento que coincide con la primera etapa de desarrollo del comercio entre Fujian y Luzón. Así, la producción marfileña de este periodo podría tratarse de una respuesta a la escultura de marfil producida en Manila por los sangleyes (Gillman 1984, 39), pues no hay que olvidar que hacia 1590 estos productos se habían convertido en un arte muy refinado según la carta dirigida por Domingo de Salazar al rey en 1590 (Salazar 1897, 66).

\section{Análisis sobre la procedencia del marfil}

El marfil fue un material abundante en Fujian dada la prosperidad del comercio ultramarino, sin embargo, se trataba de una materia prima bastante rara en China hasta mediados del siglo XVI. Su aprecio hizo que fuera uno de los principales objetos tributarios que los estados dependientes del Sudeste de Asia otorgaron al Imperio Central. Según la lista en Dongxiyangkao, que consigna la producción de todos los reinos de esta zona, tanto en Malaca como en Tailandia y Camboya se produjeron colmillos de elefante que se tributaron a la corte de la dinastía Ming (Zhang 1981, $13,27,37,45,53,68)$. Durante la primera etapa de la dinastía Ming (1368-1505) la talla de marfil se desarrolló principalmente en la corte, raramente en los ambientes populares (Huang 2012, 18). 
Tal situación cambió con la llegada de los europeos -primero los portugueses, luego los españoles y los holandeses-, quienes siempre explotaron cualquier posibilidad de negocio en Asia Oriental. En los diarios de la Compañía Neerlandesa de las Indias Orientales (Vereenigde Oostindische Compagnie), se puede verificar cómo los holandeses reunían marfil y cuerno de rinoceronte procedente de Camboya y Siam para luego transportarlo a otros puntos comerciales como Batavia y Fuerte Zeelandia (Departement van Koloniën onder toezcht van Dr. H. T. Colenbrander 1899, 64). Según De dagregisters van hetkasteel Zeelandia (Diario del Fuerte Zeelandia), el día 4 de agosto de 1637 el junco Rarop, ${ }^{16}$ que salió de Siam en julio del mismo año, llegó a Pehouw (Islas Pescadores) con 105 catti de colmillos siameses y 9 cuernos de rinoceronte (Blussé et al. 1986, 358).17 El mismo documento nos informa que el 22 de agosto de 1639, el filibote Den Otter, ${ }^{18}$ partiendo de Siam, llegó a Tayouan con "3014 catti de colmillos, ${ }^{19} 11$ picol de cera, ${ }^{20} 5$ picol de madera de agar..." (Blussé et al. 1986, 475). Estos datos nos dan una idea del intenso suministro de colmillos que se produjo, superando incluso la demanda del mercado y haciendo que los beneficios se desplomaran. En 1641, cuando el agregado comercial gestionaba unos pedidos cuyo destino era el mercado de Japón y Taijouan (Taiwan), declaraba que los colmillos y cuernos de rinoceronte eran muy baratos y se había logrado bastante cantidad (Departement van Koloniën onder toezcht van Dr. H. T. Colenbrander 1900, 52), algo que demuestra la gran cantidad de animales de este tipo que habían sido cazados en décadas anteriores.

Un porcentaje importante de los colmillos obtenidos en Camboya y Siam fueron introducidos en el mercado chino. Ante la imposibilidad de comerciar directamente con China continental, los holandeses lo hicieron a través de la Isla de Formosa (Taiwan). De hecho, capturaron los barcos que iban de Zhangzhou a Manila, obligando a los comerciantes de Fujian a negociar con Formosa. Ellos adquirían productos como porcelana y seda, y a cambio, ofrecían a los chinos otros productos como pimienta, marfil, sándalo, etc. Según los diarios de la Compañía de Indias, el 27 de noviembre de 1629, el gobernador Putmans dirigió varios yates a China con "... picol de pimientas, ${ }^{21} 50$ picol de brasilete de la india y... picol de marfil" (Blussé et al. 1986, 5). El día 2 de octubre de 1640, el comerciante Hambuangh tomó el junco de Jocsim para ir a An'hai, otro puerto de Fujian que está muy cerca de Zhangzhou, con "142.470 catti de pimienta... 9.748 catti de caetche y 8.477 catti de marfil..."(Blussé et al. 1986, 500). Estos datos nos pueden dar una idea del gran número de marfil introducido en Fujian durante la dominación holandesa en Taiwan (1624-1662) constituyendo un fuerte estímulo para la industria de marfil en Zhangzhou.

Los registros documentales en chino y holandés indican que el marfil utilizado en las figuras de Zhangzhou provenía principalmente de Asia. Sin embargo, en el caso de los marfiles hispanofilipinos, tenemos poca información sobre su origen. Un análisis científico realizado por el Instituto Andaluz de Ciencias de la Tierra con una pieza hispano-filipina de la iglesia parroquial de íllora (Granada) demuestra que esta figura de Inmaculada, definida como obra del siglo XVII, también está hecha con el marfil asiático, lo que corrobora su relación con las piezas talladas en Zhangzhou e indica que sería una obra hecha por los mismos artistas fujianeses establecidos en Manila (Rozalen and Ruiz Gutierrez 2015, 1-6).

China tuvo la tradición de tallar colmillos desde la época neolítica, aunque durante muchos siglos el marfil siempre fue un material raro y valioso que se usaba para labrar escogidos objetos rituales y de uso diario para las clases altas. Sin embargo, resulta curioso que hasta ahora se hayan encontrado muy pocas figuras de marfil que sean anteriores a la dinastía Ming (1368-1644). Además, las piezas conservadas actualmente del periodo Ming son en su mayoría del estilo Zhangzhou. Por eso, creemos que la gran evolución de la figura marfileña china tuvo lugar en el último periodo de la dinastía Ming posibilitada por un suministro suficiente de colmillos capaz de satisfacer el gran consumo de este material. Así, las denominadas figuras de "inmortales" de Zhangzhou inspiradas por las figuras hispano-filipinas y hechas por los mismos artesanos de Fujian, podrían ser el inicio de esta industria en China, e influir, a partir de aquí, en el surgimiento de la industria doméstica china de figuras de marfil. 


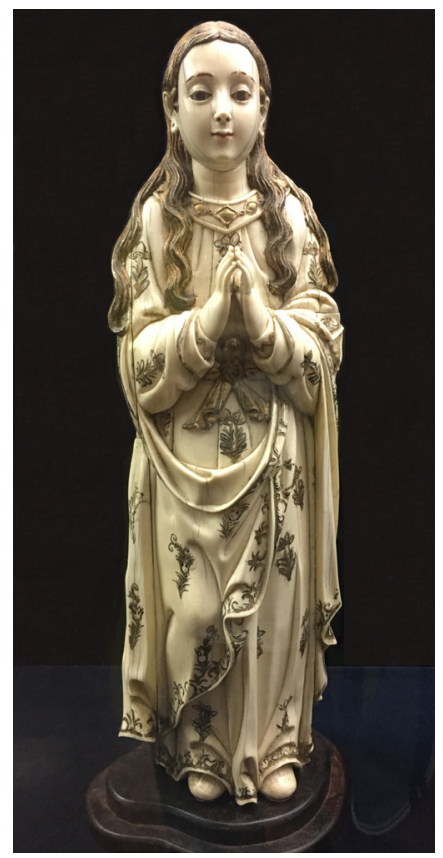

Fig. 3. Inmaculada, primera mitad del siglo XVIII, marfil, Museo Oriental, Valladolid (fotografía de la autora)

\section{La Virgen y Guanyin - ¿correspondencia iconográfica o intercambios culturales?}

Cuando hablamos del estilo artístico que presentan los marfiles hispano-filipinos, uno de los primeros elementos que se suelen resaltar es la cara achinada que presentan las figuras, siendo los ejemplos más típicos las representaciones de la Virgen (fig. 3). Las cejas altas, los ojos semicerrados, los párpados abultados, y la boca bien dibujada con las comisuras hacia arriba dan un aire suave y sonriente a estas figuras acercándolas mucho al aspecto de Guanyin (fig. 4) (Ruiz Gutiérrez 2006, 59), iconografía frecuente en el arte folklórico de Fujian y, por supuesto, en los marfiles de Zhangzhou.

En el panteón chino Guanyin es una diosa de género femenino, aunque, originalmente era una figura masculina que procedía del budismo de la India, conocido como Avalokiteśvara bodhisattva. Su nombre completo en chino es "Guan shi yin" que significa "quien oye los lamentos del mundo" y se le considera símbolo de "benevolencia". Los chinos creen que Guanyin tienen un poder sobrenatural, lo que ayuda a todos aquellos que le

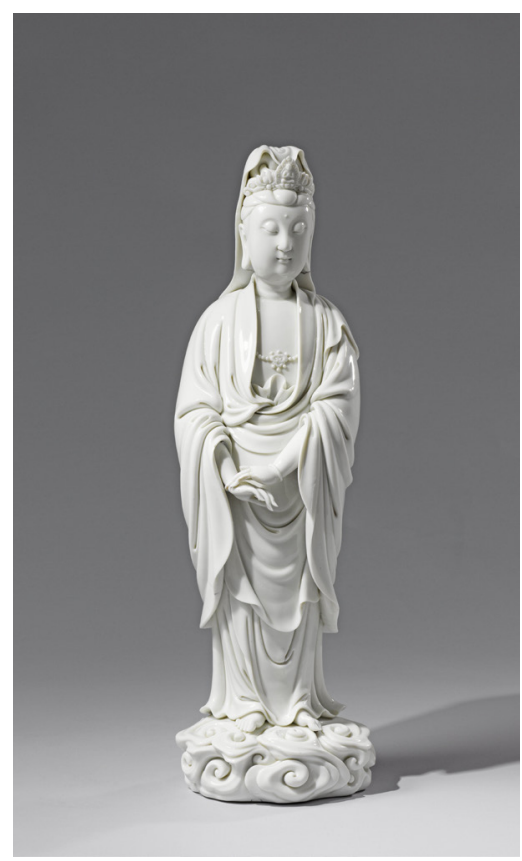

Fig. 4. Guanyin, siglo XVII, porcelana, Rijksmuseum, Amsterdam

acuden en situaciones extremas. A medida que el budismo se adaptaba a la cultura china, la figura de Guanyin iba adquiriendo aspectos achinados. Los ejemplos más típicos son algunas iconografías que se consideran completamente indígenas de China, como Shuiyue Guanyin (Guanyin con agua y luna), Baiyi Guanyin (Guanyin en túnica blanca), Yulan Guanyin (Guanyin con cesta de pescado), etc. ${ }^{22}$ Todas han sido incorporadas a las "treinta y tres manifestaciones de Guanyin" del budismo Mahayana, aunque ninguna de ellas tiene su raíz en los sánscritos clásicos. ${ }^{23}$

Otro fruto de esta adaptación cultural del budismo es que Guanyin quedó vinculada a un lugar concreto de China: el Monte de Putuo, situado en el Archipiélago de Zhoushan en el Mar de la China Oriental y considerada como su residencia. Además, adquirió un apodo peculiar: Nanhai Guanyin (Guanyin del Mar Meridional), ${ }^{24}$ lo que la convertía en una diosa marítima. ${ }^{25}$ Como la gente de las provincias costeras de Fujian y Zhejiang se dedicaba fundamentalmente a la pesca o al comercio marítimo, diosas marítimas como Guanyin y Mazu obtuvieron una gran difusión, 

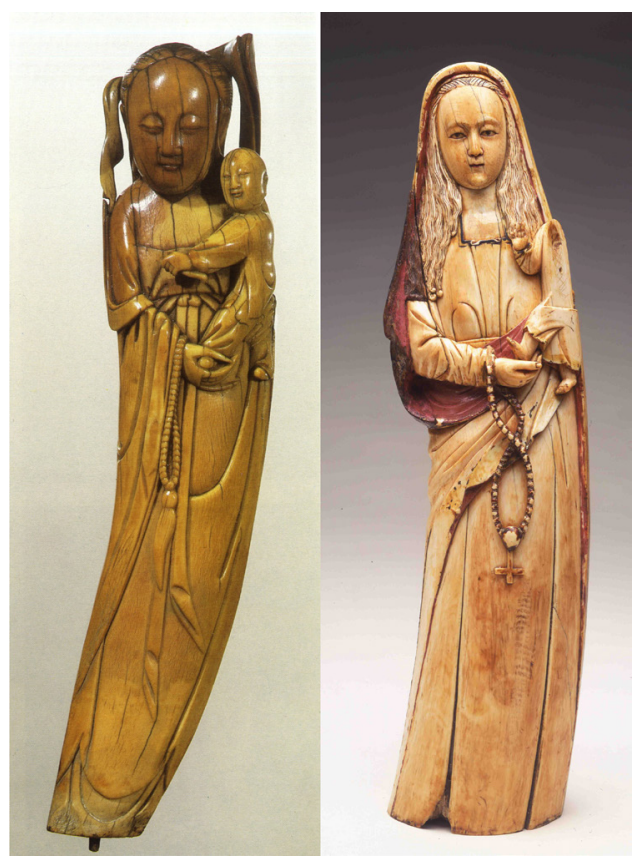

Fig. 5. Songzi Guanyin (izquierda), 1573-1644, marfil, Colección privada (Fuente: Gillman, "Ming and Qing Ivories: Figure Carving", fig. 24); Virgen del Rosario (derecha), siglo XVII, marfil, Hispanic Society of America, New York

pues, según la creencia popular eran eficaces protectoras ante las tormentas y los naufragios. Cuando Martín de Rada pisó la tierra de Fujian en 1575, le llamó la atención los ídolos venerados en la calle, y, según su relato, era "tanta la suma de los ydolos que vimos por todo lo que anduvimos que no se pueden contar porque demas que en sus templos y casas particulares para ello ay muchos...".26

Cuando los fujianeses emigraron a Filipinas, llevaron consigo sus propias tradiciones religiosas, entre las que se encontraba el culto a Guanyin. Este hecho se ha verificado dada la existencia de esta figura en los templos de las comunidades chinas en las islas (DY 2014). De ese modo, al copiar los modelos europeos, debían de pensar en las deidades de su propia religión, así que inevitablemente los combinaban con el arte del budismo chino. En el caso de la Virgen, es posible que se reinterpretara la típica expresión de Guanyin dadas las similitudes que existían entre ambas iconografías. Sin embargo, no debemos

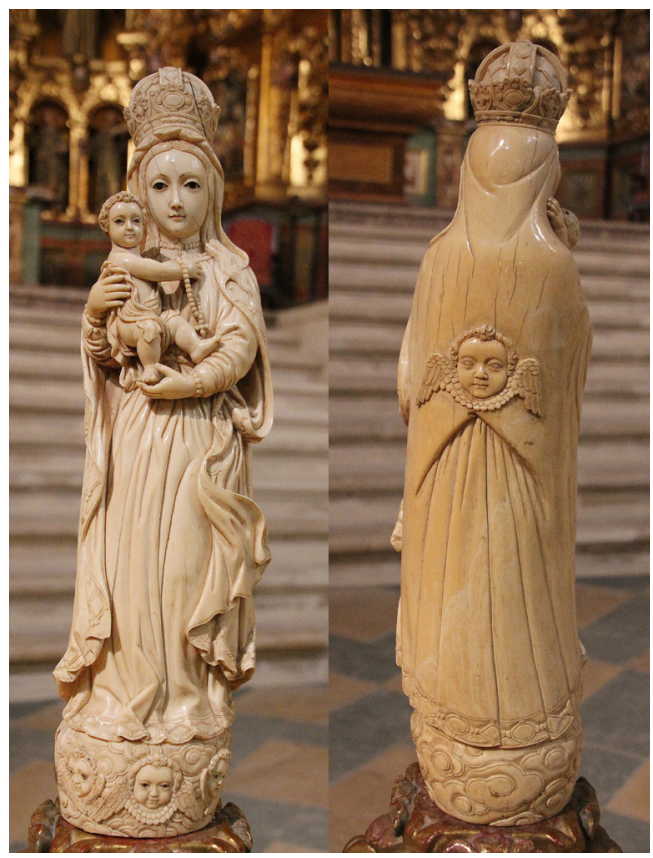

Fig. 6. Virgen del Rosario (vista frontera, izquierda), siglo XVII, marfil, Museo de San Francisco, Medina de Rioseco- Valladolid (fotografía de Fernando Fradejas); Virgen del Rosario (vista trasera de la misma figura, derecha, fotografía de Fernando Fradejas)

reducir la relación entre estas dos representaciones a una influencia lineal y unidireccional de Guanyin hacia la Virgen María, sino que podrían presentar relaciones más complejas, influyéndose mutuamente.

Un ejemplo más llamativo es el de Songzi Guanyin (fig. 5, izquierda), variante de la diosa Guanyin, a la que los fieles se encomendaban cuando deseaban tener hijos. Esta imagen, por su concreción visual (porta un niño en el brazo), está muy relacionada con el arquetipo cristiano de la Virgen con el Niño, la cual es sumamente habitual en el marfil hispano-filipino. En una sociedad agrícola como la China dinástica, la fertilidad era considerada una fuerte responsabilidad familiar, así que la petición de hijos, sobre todo varones, formaba parte indispensable de las prácticas populares religiosas. La creencia de que Guanyin era capaz de proporcionar hijos a quién se lo pedía tuvo su origen en un capítulo del Sūtra de loto (Yu 2001, 258-9), texto que fue traducido al chino en el siglo $V$. Sin embargo, aunque la 
fama milagrosa de Guanyin para "otorgar hijos" fue conocida entre el pueblo chino durante muchos siglos, su representación como portadora de un niño sobre el regazo apareció poco antes del siglo XVI. De igual forma, los exvotos sobre esos milagros pertenecen, en su mayoría, a siglos posteriores, cuando ya existía un importante contacto entre Occidente y Oriente y el cristianismo se encontraba en amplia difusión por el territorio chino.

La rareza de la figura de Songzi Guanyin antes de la Dinastía Ming y su pronta popularización a partir del siglo XVI nos hace pensar en su posible vinculación con la figura cristiana de la Virgen con el Niño. Un ejemplo típico es una figura de marfil de Songzi Guanyin que tiene mucha semejanza con otra estatua mariana asignada al estilo "sinoportugués". La figura de la Virgen del Rosario (fig. 5, derecha), perteneciente a la Hispanic Society of America de Nueva York, tiene la misma postura que la de Guanyin (fig. 5, izquierda) así como los detalles de la mano y el rosario. Aunque el Niño de la Virgen del Rosario se ha perdido, todavía observamos en la parte restante una gran similitud con la criatura que tiene en brazos de Guanyin. Muchos investigadores indican que la figura la Virgen está influenciada por Guanyin, pero Gillman opina lo contrario. Según él, esta figura de Songzi Guanyin puede estar inspirada en la imagen de la Virgen del Rosario: sustituyendo la cruz del rosario por una borla, retirando el globo en la mano del Niño y añadiendo algunos detalles chinos como la bufanda budista arqueada. De esta forma, la Virgen del Rosario se convertiría sin problemas en Songzi Guanyin (Gillman 1984, 41).

La Virgen del Rosario fue la advocación mariana más venerada por los dominicos, quienes, no lo olvidemos, tuvieron mucha influencia en Asia Oriental a partir de la segunda mitad del siglo XVI (Clarke 2013, 30). En 1587, tres sacerdotes españoles de la orden dominica llegaron a Macao y fundaron allí la Iglesia de Santo Domingo, misma construcción que más tarde quedaría en manos de los portugueses (Teixeira 1961, 60811). Por tanto, es posible que esta figura marfileña de la Virgen del Rosario fuera un encargo hecho por los dominicos en Macao a un taller chino. Aunque Gillman propone que el lugar de producción de la serie sino-portuguesa pueda ser Cantón (Gillman 1984, 36), debemos considerar la posible intervención de los artistas fujianeses, sobre todo si tenemos en cuenta la gran similitud que muestra esta figura con la de Songzi Guanyin, cuya manufactura es típica del marfil de Zhangzhou. Otro argumento que apoyaría esta teoría son los frecuentes intercambios que tuvieron lugar entre Macao y Manila, sobre todo durante la unión de las coronas de España y Portugal (1580-1640).

Pero más allá de los territorios portugueses, la Virgen del Rosario también se veneró en las Filipinas, donde los dominicos también tuvieron una gran influencia. Una figura de marfil con esta iconografía se conserva en el Museo de San Francisco en Medina de Rioseco (fig. 6, izquierda) (Estella Marcos 1984 b, 197-9), y, curiosamente, posee una peana de nubes escamosas (fig. 6, derecha). Este motivo es típico del arte chino y evoca la figura de porcelana de Guanyin producida en Dehua (fig. 4). Fue habitual que los sangleyes establecidos en Manila, al reproducir figuras europeas, incorporan elementos procedentes de su propia tradición; pero también puede ocurrir lo contrario, es decir, que combinaran elementos europeos al labrar la imagen de Guanyin. Esta suposición se comprueba en el estudio realizado por Shi Chuanmiao, donde afirma que algunas figuras de Guanyin existentes en templos chinos de las Islas Filipinas se parecen mucho a imágenes de la Virgen. Un ejemplo típico es una estatua de Guanyin del templo Fa Zang Si, cuyo peinado crespo recuerda fácilmente a la iconografía cristiana de la Virgen (Shi 2008, 86).

Por su parte, Aristotle C. DY., al estudiar la religión china en Filipinas, explica las actividades religiosas de los chinos desde un punto de vista del sincretismo. En su análisis, la religión china tiene un carácter inclusivo que acepta con facilidad otras deidades ajenas (DY 2014). En el caso concreto de Guanyin, no hay que olvidar que esta figura también tuvo un origen extranjero, y pudo adaptarse a la cultura china gracias a la gran tolerancia mantenida respecto al budismo. De ese modo, no resulta extraño que los artesanos oriundos de Fujian, acostumbrados al pluralismo cultural y religioso -por su larga tradición 
comercial-, incorporasen elementos extranjeros en el modelado de sus propias deidades.

\section{Conclusiones}

Los marfiles hispano-filipinos contribuyeron a la difusión del cristianismo en Filipinas durante el dominio hispánico. En su producción, fueron los artesanos chinos los que desempeñaron el papel más destacado. Una gran parte de ellos provenían de Zhangzhou, ciudad al sur de la provincia de Fujian que en 1567 fue convertida en el único puerto autorizado de China para comerciar con el exterior, hecho que ofreció una oportunidad sin precedentes para los negocios entre Zhangzhou y Manila.

Dado su papel de puerta principal a través de la que se realizaron los primeros contactos directos entre China y Europa, la ciudad de Zhangzhou pudo poseer una emergente industria de arte cristiano en la primera mitad del siglo XVI. Tras el establecimiento de los españoles en Filipinas, los mercaderes de Zhangzhou conocieron de ellos los marfiles cristianos. Es posible que copiaran estas figuras en su tierra natal, región en la que se había mantenido una larga tradición escultórica. Gracias al florecimiento del comercio ultramarino, se importaron un gran número de colmillos a Zhangzhou, haciendo posible el surgimiento de una industria local de marfil en esta ciudad. Los temas principales de estas piezas eran figuras religiosas chinas, que estarían inspiradas, en un sentido amplio, en las figuras cristianas hispano-filipinas.

El ejemplo más significativo para explicar la relación entre el marfil hispano-filipino y el de Zhangzhou es la gran semejanza que demuestra la figura de la Virgen María con la de Guanyin. A través de un estudio comparativo de las dos imágenes, encontramos que la influencia entre ambas era mutua, es decir, los artesanos chinos incorporaban detalles de Guanyin al modelar a la Virgen, y, al contrario, también se combinaban elementos de la Virgen al manufacturar la figura de Guanyin. Este intercambio se refleja particularmente en la iconografía de Songzi Guanyin, cuya popularidad en China a partir del siglo XVI pudo estar inspirada en la imagen de la Virgen con el Niño.

Como siempre ocurre en el mundo de historia de arte, la falta de documentación de estas piezas marfileñas, tanto de la serie hispano-filipina como de la de Zhangzhou, nos ha dejado muchas dudas que están por resolver con el descubrimiento de nuevas fuentes. Profundizar en ese tema nos ayudará, desde un punto de vista global, a conocer los intercambios culturales que se produjeron entre Occidente y Oriente durante una época de gran contacto entre ambas partes. 


\section{NOTAS}

1 La investigación ha sido financiada por China Scholarship Council. Agradezco a Adrián Contreras Guerrero por su ayuda en la redacción del texto en idioma castellano.

2 Otras publicaciones importantes son Beatriz Sánchez Navarro de Pintado, Marfiles cristianos del Oriente en México (México: Fomento Cultural Banamex, 1986); Regalado Trota José, Images of Faith-Religious Ivory Cavings from The Filippines (Pasadena: Pacific Asia Museum, 1990); José Manuel Casado Paramio, Museo Oriental de VaIladolid, Catálogo II: marfiles hispanofilipinos (Valladolid: Museo Oriental de Valladolid, 1997); Ana Ruiz Gutiérrez, 'La iconografía mariana en la eboraria hispano filipina: la Virgen del Niño Perdido de Caudiel, Castellón', Millars. Espai i Història, no. 29 (2006), 57-65; Marjorie Trusted, "Propaganda and Luxury Small-Scale Baroque Sculptures in Viceregal America and the Philippines", in Asia and Spanish America: TransPacific Artistic and Cultural Exchange, 1500-1850, ed. DonnaPirceand Ronald Otsuka (Denver: Denver Arte Museum, 2009), 151-63; Ana Ruiz Gutiérrez, "Marfiles hispano-filipinos", 184-212.

3 Cabe destacar es el estudio de Derek Gillman, que hizo un análisis maravilloso de las interacciones entre el marfil de Zhangzhou y las figuras hechas para el mercado portugués e hispánico, dándonos materiales importantes para profundizar en esa línea. Derek Gillman, "Ming and Qing Ivories: Figure Carving", in Chinese Ivories from the Shang to the Qing: An Exhibition Organized by the Oriental Ceramic Society Jointly with the British Museum, 24 May to 19 August 1984 in Oriental Gallery II, ed. William Watson (London: Oriental Ceramic Society, British Museum Publications Ltd, 1984), 35-117.

${ }^{4}$ Algunas publicaciones sobre las interacciones culturales entre la Virgen y Guanyin se pueden ver en Lauren Arnold, Princely Gifts and Papal Treasures: The Franciscan Mission to China and Its Influence on the Art of the West, 1250-1350 (San Francisco: Desiderata Press, 1999); Jeremy Clarke, The Virgin Mary and Catholic Identities in Chinese
History (Hong Kong: Hong Kong University Press, 2013); Maria Reis-Habito, 'The Bodhisattva Guanyin and the Virgin Mary', Buddhist-Christian Studies, no.13 (1993), 61-69; Eva Zhang, 'Kannon-Guanyin-Virgin Mary: Early Modern Discourses on Alterity, Religion and Images', in Transcultural Turbulences: Towards a Multi-Sited Reading of Image Flows, ed. Christiane Brosius and Roland Wenzlhuemer (Berlin, Heidelberg: Springer, 2011), 171-89; Aristotle C. DY, 'The Virgin Mary as Mazu or Guanyin: The Syncretic Nature of Chinese Religion in the Philippines', Philippine Sociological Review, no. 62 (2014), 41-63.

5 Carta de Legazpi sobre falta de socorro y descubrimientos, Archivo General de Indias, FILIPINAS, 6, R. 1, N. 7.

6 Océano Este (東洋) y Océano Oeste (西洋): conceptos geográficos chinos de ciertas regiones del Mar del Sur. El rango concreto de tales conceptos tuvo varios cambios a lo largo de la historia. Según Dongxiyangkao, libro publicado en 1617 por Zhang Xie, la gente de Zhangzhou tomaba la Isla Kalimandan como lugar de separación del Océano Este y el Océano Oeste. Al Océano Este correspondía los reinos de Luzón, Sulu, Moluca, Brunei, etc., mientras que el Océano Oeste concluía lugares como Jiaozhi (nombre antiguo del norte de Vietnam), Zhancheng (Champa), Siam, Camboya, Malaca, etc. Zhang Xie, Dongxiyangkao (東西洋 考) (Beijing: Zhonghua Shuju, 1981).

7 Yadong (壓冬), término que se refiere al hecho de que los comerciantes chinos se quedaron en Luzón y pasaron el invierno allí antes de volverse a China.

8 Relación del descubrimiento y conquista de la isla de Luzón y Filipinas hecha por el maestre de campo Martín de Goiti, 1570, Archivo General de Indias, PATRONATO, 24, R.17, fol.6, v.

9 Relación del descubrimiento, conquista de Luzón, 20 de abril de 1572, Archivo General de Indias, PATRONATO, 24, R.25, fol.10, v.

${ }^{10}$ Carta de la Audiencia de Manila sobre situación en Filipinas, Archivo General de Indias, FILIPINAS, 18A, R.6, N.40.

${ }^{11}$ Relacion muy cierta y verdadera de lo que agora nuevamente se ha sa- bido de las nuebas Islas del Poniente y descubrimiento que dicen de la China que escribe Hernando Riquel Escrivano de la Governación dellas à un su Amigo a Mexico, la qual vino en los Navios que estaban juntos en el Fuerte de Capulco, y de la gran riqueza dellas y de los tractos y Mercaderías de los Chinas, y de la manera que sacan y benefician el Oro; y otra relación de las nuebas que han venido de Italia y Fortificación de Tunez, y de la Armada grande del Turco, y como ha tractado de reducirse la Ciudad de Ginebra de la obediencia de la Madre Santa Iglesia y ultimamente la muerte del Chistianisimo Rey de Francia y de lo que pasa en Paris y en Flandes. Vá también el Epitafio que se halló aqui del Bienaventurado Rey D Fernando que ganó a Sevilla 1574. Archivo del Museo Naval. Colección Fernández de Navarrete, Nav. II, fol. 247, dto. $7^{\circ}$.

12 Sobre la experiencia de Galeote Pereira véase Charles Ralph Boxer, South China in the Sixteenth Century (1550-1575): Being the Narratives of Galeote Pereira, Fr. Gaspar da Cruz, O.P., Fr. Martin de Rada, O.E.S.A., (1550-1575) (Farnham: Ashgate Publishing, 2011), I-Iviii.

${ }^{13}$ Shoushan: pueblo del norte de Fujian cuya producción más famosa es la piedra de buena calidad que se usa en la escultura. Putian: ciudad situada en la costa central de Fujian que cuenta con una historia milenaria en el ámbito de la escultura de madera.

14 Agradezco a David Sevillano López por su ayuda en la traducción del poema chino.

15 Haicheng: distrito de Zhangzhou donde estaba el puerto de la Luna.

16 Junco (en holandés: jonk), término de un tipo de barco chino. La pronunciación es similar a la palabra "chun" (barco) del dialecto minnanhua, por lo que el "junco" de esta crónica holandesa puede referirse al barco típico de Fujian conocido como fuchuan ( 福船).

17 Catti (en chino: 斤): unidad de masa tradicional de Asia Oriental. 1 cat$\mathrm{ti}=590 \sim 600 \mathrm{~g}$

18 Filibote (en holandés: fluyt): un tipo de velero muy utilizado por la Compañía de Indias durante los siglos 
XVII-XVIII, cuyo diseño era similar al de los galeones.

19 Tayouan (en chino: 大員, en otros casos también escrito como "Taijouan" o "Taioan"): nombre de un antiguo lugar de Taiwan donde se situaba el puerto de transbordo comercial de los holandeses durante el siglo XVII. Está en el actual Distrito Anping de la ciudad de Tainan. En los documentos holandeses ese término también se refiere a la denominación de toda la Isla de Formosa, lo que derivó en el actual nombre de "Taiwan".

20 Picol: peso que sirve en China para pesar la seda y otras mercancías. 1 picol $=133.3$ libras $=60.47$ kilogramos $=100$ catti. George Bryan Souza, The Survival of Empire: Portuguese Trade and Society in China and the South China Sea, 1630-1754. (Cambridge: Cambridge University Press, 1986), xvi-xvii.
21 Yate (en holandés: jacht): un tipo de bricbarca militar del siglo XVII.

22 Sobre las iconografías de Guanyin en el budismo Mahayana de China, véase Yu, Kuan-Yin: The Chinese Transformation of Avalokitesvara; Zhou Qiuliang, Guanyin gushi yu guanyin xinyang yanjiu: yi suwenxue wei zhongxin (觀音故事與觀音信仰研究: 以俗文學為 中心ا,). (Guangzhou: Guangdong Higher Education Press, 2011).

23 Dentro de las "treinta y tres manifestaciones de Guanyin" del Mahayana, la mayoría provienen de las "treinta y tres manifestaciones de Avalokiteśvara" descritas en el Sutra de Loto. No obstante, sólo hemos aludido a las creaciones originales de los chinos que nunca han sido mencionado en los sutras. Yu, Kuan-Yin: The Chinese Transformation of Avalokitesvara, 14.

${ }^{24}$ Sobre el origen del apodo Nanhai Guanyin, véase. Zhou, Guanyin gushi yu guanyin xinyang yanjiu: yi suwenxue wei zhongxin, 341-48.

25 Sobre el culto a Guanyin entre el pueblo marítimo de Asia Oriental, véase Chen Yunv, "Guanyin yu haiyang: mingdai dongnan yanhai de guanyin xinyang" (觀音與海洋:明代東南沿海 的觀音信仰)', Humanistic Buddhism: Journal, Arts and Culture (人間佛教: 學 報.藝文)， no. 2 (2016)，102-33.

${ }^{26}$ Relaçion Verdadera de las cosas del Reyno de TAIBIN por otro nombre china y del viaje que a el hizo el muy Reverendo padre fray martin de Rada provinçial que fue de la orden del glorioso Doctor delayglesia San Agustin. Que lo vio yanduvo en la provinçia de Hocquien año de 1575 hecha por el mesmo, Bibliothèque nationale de France, Espagnol 325, fol.29, v. 


\section{REFERENCIAS}

Arnold, Lauren. Princely Gifts and Papal Treasures: The Franciscan Mission to China and Its Influence on the Art of the West, 1250-1350. San Francisco: Desiderata Press, 1999.

Blussé, J. L., M.E. Van Opstall, Yung-Hao Ts'ao, Shu-Sheng Chiang, and W. Milde. De Dagregisters van Het Kasteel Zeelandia, Taiwan, 1629-1662. Deel I: 1629-1641. 'S-Gravenhage: Martinus Nijhoff, 1986.

Boxer, Charles Ralph. South China in the Sixteenth Century (1550-1575): Being the Narratives of Galeote Pereira, Fr. Gaspar da Cruz, O.P., Fr. Martin de Rada, O.E.S.A., (1550-1575). Farnham: Ashgate Publishing, 2011.

Boy, Jaime. Diccionario teórico, práctico, histórico y geográfico de comercio, Tomo. IV. Barcelona: Imprenta de Valentín Torras, 1840.

Cai, Meifen. "Gangbu de gongyi: guanyu mingmogingchu zhangzhou gongyipin ersanshi" ( 港埠的工藝: 關於明末清初漳州工藝品二三事 Artesanía del puerto, dos o tres cosas sobre las artesanías de Zhangzhou al final de la dinastía Ming e Inicio de la dinastía Qing)." In Zhongguo haiyang fazhanshi lunwenji (中國海洋發 展史論文集 Recopilación de los artículos sobre la historia de desarrollo marítimo de China), Vol. IX, edited by Liu, Xufeng, 39-87. Taipei: Research Center for Humanities and Social Sciences, 2005.

Casado Paramio, José Manuel. Museo Oriental de Valladolid, Catálogo II: Marfiles hispanofilipinos. Valladolid: Museo Oriental de Valladolid, 1997.

Chen, Liangcai. "Qikepianxu (七克篇序 Prólogo del capítulo de siete vencimientos)." In Tianxue chuhan (天學初函 Recopilación de los libros del catolicismo), edited by Zhizao Li, 303-4. Shanghai: Shanghai Jiaotong University Press, 2013.

Chen, Yunv. "Guanyin yu haiyang: mingdai dongnan yanhai de guanyin xinyang (觀音與 海洋: 明代東南沿海的觀音信仰 Guanyin y el mar: el culto a Guanyinen la costa del sureste en la dinastía Ming)." Humanistic Buddhism: Journal, Arts and Culture (人間佛教: 學報.藝 文) 2 (2016): 102-33.
Clarke, Jeremy. The Virgin Mary and Catholic Identities in Chinese History. Hong Kong: Hong Kong University Press, 2013. https://doi.org/10.5790/hongkong/9789888139996.001.0001

Departement van Koloniën onder toezcht van Dr. H. T. Colenbrander. Dagh-register gehouden int Casteel Batavia vant passerende daer ter plaetse als over geheel Nederlandts-India, Anno 1636. 'S-Gravenhage: Martinus Nijhoff, 1899.

Departement van Koloniën onder toezcht van Dr. H. T. Colenbrander. Dagh-register gehouden int Casteel Batavia vant passerende daer ter plaetse als over geheel Nederlandts-India, Anno 1641-1642. 'S-Gravenhage: Martinus Nijhoff, 1900.

DY, Aristotle C. "The Virgin Mary as Mazu or Guanyin: The Syncretic Nature of Chinese Religion in the Philippines." Philippine Sociological Review 62 (2014): 41-63.

Estella Marcos, Margarita Mercedes. "Algunos relieves en marfil hispano-filipinos y sus posibles fuentes de inspiración." Archivo español de arte 43, no. 170 (1970): 151-79.

Estella Marcos, Margarita Mercedes. "El comercio de imágenes de España con América y Filipinas: algunos ejemplos." Cuadernos de arte colonial 5 (1989): 67-80.

Estella Marcos, Margarita Mercedes. "Vírgenes de marfil hispano-filipinas." Archivo español de arte 40, no. 160 (1967): 333-58.

Estella Marcos, Margarita Mercedes. La escultura barroca de marfil en España: las escuelas europeas y las coloniales, Texto y láminas, Vol. I. Madrid: Instituto Diego Velázquez del CSIC, 1984 a.

Estella Marcos, Margarita Mercedes. La escultura barroca de marfil en España: las escuelas europeas y las coloniales, Catálogo. Vol. II. Madrid: Instituto Diego Velázquez del CSIC, 1984 b.

Fang, Chenchen. "Research on Tempest of Round Taiwan Sea in the Late 17th Century: A Study Based on Spanish Sources (從西班牙史料考 察十七世紀末期環臺灣海域的暴風雨紀錄)." Taiwan Historica (臺灣文獻) 58, no. 4 (2007): 125-52. 
Fang, Chenchen. El comercio entre los sangleyes y Luzón (1657-1687): análisis, traducción y anotación de las fuentes, Tomo / (華人與呂宋 貿易[1657-1687]: 史料分析與譯註，第一冊). Hsinchu: National Tsing Hua University Press, 2012.

Ferrão de Tavares e Távora, Bernardo. Imaginaria Luso-Oriental. Lisboa: Imprensa Nacional Casa da Moeda, 1983.

Gao, Lian. Zunshengbajian (遵生八箋 Ocho notas para preservar la salud). Beijing: Renmin Weisheng Chubanshe, 1994.

Gao, Meiqing, ed. Chinese Ivories from the Kwan Collection (關氏所藏中國牙雕). Hong Kong: Art Gallery - the Chinese University of Hong Kong, 1990.

Gillman, Derek. "Ming and Qing Ivories: Figure Carving." In Chinese Ivories from the Shang to the Qing: An Exhibition Organized by the Oriental Ceramic Society Jointly with the British Museum, 24 May to 19 August 1984 in Oriental Gallery II, edited by William Watson, 35-117. London: Oriental Ceramic Society, British Museum Publications Ltd., 1984.

Gu, Bingqian et al. Mingshenzong shilu (明神宗 實錄 Crónica del emperador Shenzong de la dinastía Ming). Taipei: Institute of History and Philology, Academia Sinica, 1962.

Huang, Qiaomei. "A Priliminary Study on the Ancient Ivory Figurines (古代牙雕人物造像的 初步研究)." Master diss, Xiamen University, 2012.

Institute of History and Philology, Academia Sinica, ed. "Tianqi hongben shilu canye (天啟紅 本實録殘葉 Hojas restas de la versión roja de Tianqi de la cronología de la dinastía Ming)" In Mingqing shiliao wubian (明清史料戊編 Quinta recopilación de los documentos históricos de Ming y Qing), 67. Taipei: Institute of History and Philology, Academia Sinica, 1987.

Li, Jinming. Zhangzhougang: mingdai haicheng yuegang xingshuaishi (漳州港: 明代海澄月港 興衰史 El puerto de Zhangzhou, historia del florecimiento y decadencia del puerto de la Luna en Haicheng durante la dinastía Ming). Fuzhou: Fujian Renmin Chubanshe, 2001.
Medina, Juan Ruiz de. Documentos del Japón, 1558-1562, Vol.148. Roma: Instituto Histórico de la Compañía de Jesús, 1995.

Min, Mengde. Wanli guichou zhangzhou fuzhi (萬曆癸醜漳州府志 Cartografía de la prefectura de Zhangzhou elaborada en 1613 del reinado de wanli) 27, "Wuchan. Qizhishu." Xiamen: Xiamen University Press, 2012.

Museo de Tianyige. Wanli ershisannian yiweike jinshi lvli bianlan (萬曆二十三年乙未科進士履 歷便覽 Repaso del curriculum vitae de los doctores admitidos en el año veintitrés de Wanli). Ningbo: NingboshiChubanshe, 2006.

Ollé, Manel. La empresa de China: de la Armada Invencible al Galeón de Manila. Barcelona: EI Acantilado, 2002.

Regalado Trota, José. Images of Faith: Religious Ivory Cavings from the Filippines. Pasadena: Pacific Asia Museum, 1990.

Reis-Habito, Maria. "The Bodhisattva Guanyin and the Virgin Mary." Buddhist-Christian Studies 13 (1993): 61-69. https://doi. org/10.2307/1389874

Rozalen, Marisa, and Ana Ruiz Gutiérrez. "A Study of the Origin and Gilding Technique of a Hispano-Philippine Ivory from the XVIIth Century." Journal of Archaeological Science: Reports 4 (2015): 1-7. https://doi.org/10.1016/j. jasrep.2015.08.034

Ruiz Gutiérrez, Ana. "El tráfico artístico entre España y Filipinas (1565-1815)." PhD diss., Universidad de Granada, 2003.

Ruiz Gutiérrez, Ana. "La iconografía mariana en la eboraria hispano-filipina: la Virgen del Niño Perdido de Caudiel, Castellón." Millars. Espai i Història 29 (2006): 57-65.

Ruiz Gutiérrez, Ana. "Los marfiles hispano-filipinos en Granada." Cuadernos de arte. Universidad de Granada 38 (2007): 291-304.

Ruiz Gutiérrez, Ana. "Marfiles hispano-filipinos: protagonistas en el intercambio cultural de la Nao de China." In La Nao de China, 15651815: navegación, comercio e intercambios culturales, edited by Salvador Bernabéu Albert, 184-212. Sevilla: Universidad de Sevilla, 2013. 
Salazar, Domingo de. "Carta-relación de las cosas de la China y de los chinos del parián de Manila, enviada al rey Felipe II por Fr. Domingo de Salazar, O. P, primer obispo de Filipinas. desde Manila, á 24 de Junio, de 1590." In Archivo del bibliófilo filipino: recopilación de documentos históricos, científicos, literarios y políticos, y estudios bibliográficos, Tomo.III, edited by W. E. Retana, 47-80. Madrid: Viuda de M. Minuesa de los Ríos, 1897.

Sánchez Navarro de Pintado, Beatriz. Marfiles cristianos del Oriente en México. México: Fomento Cultural Banamex, 1986.

Shen, Dingjun et al, ed. Guangxu zhangzhoufuzhi (光緒漳州府志 Cartografía de la prefectura de Zhangzhoufu del reinado de Guangxu). Shanghai: Shanghai Shudian Chubanshe, 2000.

Shi, Chuanmiao. "The Introduction and Growth of Buddhism in the Philippines (菲律賓佛教 之傳入與發展): 1937-2008." Hsuan Chuang University, 2008.

Shurtz, William Lytle. El Galeón de Manila, translatedby Pedro Ortiz Armengol, Madrid: Ediciones de Cultura Hispánica del Instituto de Cooperación Iberoamericana, 1992.

Souza, George Bryan. The Survival of Empire: Portuguese Trade and Society in China and the South China Sea, 1630-1754. Cambridge: Cambridge University Press, 1986. https:// doi.org/10.1017/CBO9780511563454

Teixeira, Manuel. Macau e a sua diocese, III. As ordenes e congregações religiosas em Macau. Macau: Tipografia Soi Sang, 1961.
Trusted, Marjorie. "Propaganda and Luxury SmallScale Baroque Sculptures in Viceregal America and the Philippines." In Asia and Spanish America: Trans-Pacific Artistic and Cultural Exchange, 1500-1850, edited by Donna Pirce and Ronald Otsuka, 151-63. Denver: Denver Arte Museum, 2009.

Wicki, Josef. Documenta Indica V 1561-1563, Monumenta Missionum Societatis lesu, Vol. 83. Roma: Apud Monumenta Historica Soc. lesu, 1958.

Yu, Chunfang. Kuan-Yin: The Chinese Transformation of Avalokitesvara. New York: Columbia University Press, 2001.

Znang, Xie. Dongxiyangkao (東西洋考 Relato sobre el Océano Este y Oeste). Beijing: Zhonghua Shuju, 1981.

Zhang, Eva. "Kannon-Guanyin-Virgin Mary: Early Modern Discourses on Alterity, Religion and Images." In Transcultural Turbulences: Towards a Multi-Sited Reading of Image Flows, edited by Christiane Brosius and Roland Wenzlhuemer, 171-89. Berlin Heidelberg: Springer, 2011. https://doi.org/10.1007/978-3-64218393-5_8

Zhou, Qiuliang. Guanyin gushi yu Guanyin xinyang yanjiu: yi suwenxue weizhongxin (觀音故 事與觀音信仰研究. 以俗文學為中心 Estudio de los cuentos de Guanyin y el culto a Guanyin. Toma como ejemplo la literatura vulgar). Guangzhou: Guangdong Higher Education Press, 2011.

Zóbel de Ayala, Fernando. Philippine Religious Imagery. Manila: Ateneo de Manila, 1963. 
